\title{
Research on Blended Learning of Economics \& Management Courses in Higher Vocational Colleges under the Background of Big Data
}

\author{
Xu Qiaomei \\ Chongqing Business Vocational College, Chongqing, 401331, China
}

Keywords: Big data; higher vocational colleges; economics \& management courses; blended learning

\begin{abstract}
With the continuous development of market economy, there are an increasing number of higher vocational colleges offering courses relevant to economics and management, laying a foundation for training professional talents in China. In the era of big data, the classroom teaching mode is also changing. The blended learning is gradually applied to the teaching of economics \& management courses, and results have proved that it can effectively improve the teaching efficiency and quality. This is also a key way to realize quality-oriented education of students and improve their comprehensive ability under the background of educational system reform in China. Moreover, it is also of great significance to promote the long-term development of higher vocational colleges. By analyzing the basic connotation and advantages of the blended teaching mode, the author analyzed the problems in the blended learning of economics \& management courses in higher vocational colleges and explored its implementation strategies under the background of big data.
\end{abstract}

Strengthening the integration of education with information technology is not only the requirement of China's education development, but also the key way of education reform in the age of big data. Higher vocational education has been highly concerned by the education department in China, because it can continuously provide comprehensive professional talents for the country and society and inject new vitality into the economic development of China. Many higher vocational colleges have realized the necessity of the innovation and reform of teaching mode under the background of big data, and they have introduced network information technology to promote the change of classroom teaching. Economics \& management courses involve complicated contents and are highly professional and practical. The application of blended learning can enhance the teaching effect and help students to master basic theoretical knowledge and skills while improving their practical ability. However, the blended learning has some problems such as lack of experience and weak awareness of application, due to the late start of this mode. In this context, to strengthen the research of blended learning under the background of big data is of great significance to promote the reform of economics \& management courses in higher vocational colleges and increase the talent reserve in China.

\section{The Basic Connotation and Application Advantages of Blended Learning}

\subsection{The basic connotation of blended learning}

Blended learning is a product of the development of the information age. Especially under the background of big data, teaching activities can realize the integration of classroom teaching, experiment teaching, online teaching and social practice teaching by means of advanced technology and equipment, which enhances the level and richness of teaching modes. In the application of blended learning, teachers can realize the blend of teaching resources, teaching models and evaluation methods, which is very important to enhance students' interest in learning and enhance their enthusiasm and initiative in participating in learning.

\subsection{The application advantages of blended learning}

In the teaching of economics \& management courses in higher vocational colleges, the contents which are multifarious and rich not only make teachers feel difficult in their teaching but also make students feel difficult in learning. The application of blended learning can make the key points and difficulties of teaching much clearer and help teachers to realize the re-integration of teaching contents by using high-quality network resources, thereby improving teaching efficiency. Students can also break through 
the limitations of time and space and enhance the autonomy of learning through the teaching resources shared by teachers on the network platform ${ }^{[1]}$. Through the application of data analysis technique, teachers can effectively master students' learning characteristics, identify problems they encounter in the learning, and then take targeted measures to achieve continuous optimization and adjustment of blended learning. Case teaching is an important part in the teaching of economics \& management courses. Blended learning can help to obtain more typical cases, and thus it can enhance the interaction between students and teachers, and thereby help them improve their ability of practical application in analysis and discussion.

\section{The Problems of Blended Learning in Economic \& Management Courses in Higher Vocational Colleges}

\subsection{The obstacles in the integration of teaching contents}

Under the background of big data, the network teaching resources are more abundant and diverse, and the teaching of economics \& management courses in higher vocational colleges can also realize the construction of blended learning through network teaching resources. However, the difficulty in this process is the integration of teaching contents. A lot of network teaching resources cannot adapt to the characteristics of current economic \& management courses in higher vocational colleges, resulting in different classroom design, teaching methods and objectives. That the integration of network resources is limited is not conducive for teachers to construct the blended learning.

\subsection{Low level of network supervision}

Blended learning is highly dependent on the network, while various temptations in the network affect students' learning effect. Once teachers cannot effectively supervise students' learning progress, their learning effect will be poor. The virtualization of network also lead to restrictions on online teaching and testing, which is not conducive to the implementation of the teaching plan of economics \& management courses.

\subsection{The low overall quality of teachers}

The comprehensive quality of many teachers engaged in economics \& management courses of higher vocational colleges is not high, which also has impacts on the development of blended learning. Restricted by the traditional teaching concept, a large number of teachers lack a deep understanding of blended learning under the background of big data, and their own application ability of network information technology is poor, which limits the innovation and reform of teaching mode. Higher vocational colleges have also failed to realize the importance of the construction of a network information platform in the era of big data, resulting in the lack of perfect platform support for the development of blended learning.

\section{The Implementation Strategies of Blended Learning in Higher Vocational Colleges under the Background of Big Data}

\subsection{Create teaching situations}

The importance of economic law is self-evident among the courses of economics \& management in higher vocational colleges, because it is a key course to improve students' ability of practical application. In order to enhance the application effect of blended learning, teachers need to gradually cultivate students' comprehensive practical ability by creating mock courts. The mock court can enhance students' interest in participation, improve their enthusiasm and initiative, and give full play to their subjective initiative in the classroom, thereby improving teaching efficiency. In the mock court, students can sort out the knowledge they have learnt, find out problems and then analyze and solve them in the simulation process, which certainly enhances the classroom teaching effect.

Teachers must make adequate preparations for the opening of every mock court, strictly control all links such as case selection, litigation process and group discussion. When the students deviate from each other in the discussion process, the teacher, as the guide, should correct it in time. Students are often 
unfamiliar with the litigation process. In order to improve the implementation effect of the mock court, the teacher should not only ask students to prepare sufficient knowledge of management, but also arrange tasks for them to understand the trial process through the network. Additively, teachers should present reasonable role assignment according to students' characteristics of personality and ability of learning, so as to ensure that every student can learning something and improve his practical application ability in this process. In the process of summarizing and evaluating, teachers should adopt diversified criteria to evaluate students from various aspects, such as their enthusiasm for participation, ability of explore problems, capacity of analyze and solve problems, and this can enhance their learning confidence.

\subsection{Implement flipped classroom}

The application of flipped classroom is also an important way to enhance the teaching effect of blended learning. It can guide students to explore knowledge independently after class, enhance their communication and interaction in class, allows them really participate in the learning process, and enhance their enthusiasm and initiative in learning. The application of flipped classroom is a subversion of the traditional teaching mode of economics \& management courses, and is also the key to improving teaching efficiency under the background of big data. The course related to economics and management highlights the explanation and analysis of cases. The mode flipped classroom can enhance the interaction of students in case analysis and avoid the low participation of students in the traditional teaching mode.

Under the background of big data, teachers should give full play to the advantages of smart phones and APPs to provide students with high-quality teaching resources through WeChat or micro-blog, such as self-made micro-lecture videos and online case videos ${ }^{[2]}$. Through online learning, students can break through the limitations of time and space, realizing the expansion of teaching classes. Since students can have a certain understanding of the content to be learnt through the network, teachers can spend more time guiding students to analyze and discuss cases with the knowledge they have learned in classroom teaching, rather than explaining theoretical knowledge. In order to enhance the classroom atmosphere, teachers can make reasonable grouping according to students' learning level, helping them learn from each other through discussion and allowing them to master knowledge mote comprehensively. Teachers should play a leading role in their discussions to guide students correctly and give students sufficient time to express their views. It is necessary for teachers to summarize and evaluate to the whole process and students' performance after the discussion, so as to lay the foundation for the next flipped classroom. Teachers should make full use of the advantages of big data to seize students' learning interests and providing high-quality educational resources for them. In this way, they can reasonably design flipped classroom and improve students' ability of practical application.

\subsection{Give full play to the advantages of network tools}

Under the background of big data, to improve the teaching effect of the blended learning of economics \& management courses requires teachers to fully utilize network tools to realize the reform and innovation of the teaching mode. The application of network information technology and data analysis technology helps to create an advanced "Internet + teaching" mode. At the same time, teachers must give full play to the advantages of smart phones, applications and online teaching platforms to build a diversified blended learning system to effectively improve the teaching effect of economic \& management courses. Many higher vocational colleges have established network teaching platforms. By adding teaching resources about economics \& management, teachers can include related language points, principles, hot topics and cases to help students achieve autonomous learning. Micro-lecture videos greatly improve students' learning efficiency, enhance the communication and interaction between teachers and students, and realize the sharing of information resources. It is feasible for teachers to publish teaching resources and get feedback from students by creating WeChat groups or other forms. This can not only help teachers understand students' learning situation, but also prevent students from being limited by time and space, so that they can make full use of their spare time to complete autonomous learning of related knowledge. Under the background of big data, teachers can analyze students' learning effect more conveniently. This is helpful for teachers to adjust their teaching plans in 
time according to the information obtained and to explore blended learning that is more in line with the learning characteristics of students nowadays.

\subsection{Set up experiment teaching reasonably}

For economics \& management courses in higher vocational colleges, experiment teaching can give full play to the advantages of blended learning and enhance students' ability of practical application. In the past, experiment teaching only received little attention due to the limitation of teaching equipment and other factors ${ }^{[3]}$. Under the background of big data, the application of various advanced teaching equipment and technologies has provided support for the development of experiment teaching, and it is also a key way to improve students' comprehensive ability in line with the market demand. Experiment teaching requires high comprehensive ability of students. Therefore, teachers must well analyze students' learning situation before class and fully grasp their theoretical knowledge level as well as learning ability, so as to formulate a reasonable plan for experiment teaching. Teachers also need to combine network resources with experiment teaching to break through the limitations of the original teaching material contents and forms. At the same time, they should also effectively integrate various teaching resources to create blended learning that meets the learning characteristics of students nowadays. It is feasible to strengthen the design of online teaching and reasonably use task-driven teaching method to exert students' creativity in experiment courses. The online teaching mode can help students quickly acquire high-quality learning resources and improve their learning efficiency. On the other hand, the online teaching can enhance the communication and interaction between students and teachers. It can help teachers solve the problems that students encounter in the experiment course in time by answering questions in real time. In this way, teachers can master students' learning progress and effect in real time and urge them to complete their learning tasks in time, so as to promote them have skillful control of experiment cases and operation platforms. Face-to-face teaching is actually a process in which teachers guide students to discuss problems that they encounter in the study of experiment courses related to economics \& management. In this process, students can enhance their understanding of the theoretical knowledge and improve their ability to solve practical problems through cooperative experiment and experiment summary.

\subsection{Set up evaluation links reasonably}

The evaluation of blended learning is of great significance in discovering the problems of teaching, summarizing experience teaching in time and continuously improving teaching methods and concepts. In addition to avoiding a single evaluation model that only focuses on the result of paper tests, teachers should establish a diversified evaluation system and adopt rich evaluation methods, such as teacher evaluation, supervision evaluation, self-evaluation, mutual evaluation, and so on. It is necessary to include online learning assessment, classroom performance and learning progress in the assessment criteria and then conduct a comprehensive assessment of students from various aspects, which will help to tap students' learning potential and enhance their self-confidence in learning ${ }^{[4]}$. In order to enhance students' practical ability, it is needed to evaluate their investigation reports and papers and urge them to pay more attention to the cultivation of practical application ability in their daily study. This is also a main goal of blended learning. The combination of online evaluation and offline evaluation will help teachers make a comprehensive analysis of the whole blended learning and clarify the drawbacks in the application of this teaching mode. Teachers must adjust the teaching mode in time according to the teaching contents and students' learning characteristics and try the best to improve the teaching effect of economics \& management courses by clarify the focus and goal of teaching reform with the help of big data analysis technology.

\section{Conclusion}

Blended learning is an advanced teaching mode under the background of big data. It can effectively improve the teaching efficiency of economics \& management courses in higher vocational colleges and is of great significance in eliminating the drawbacks of the traditional teaching mode. With the help of advanced technology and equipment, the full use of network resources can be realized and students' 
enthusiasm and initiative for participating in learning can be enhanced. Only by the further exploration and innovation of blended learning can we build a foundation for the training of comprehensive talents.

\section{Reference}

[1] Zhang Wukang, Guo Guanke, Yang Jianquan. Construction of Blended Teaching Model for College Economics and Management Courses with the Mobile Terminal [J]. Higher Education Forum, 2018 (06): 37-41.

[2] Li Yuhong, Guan Jinqiu, Yu Shanbo. Research on the Reform and Practice about Blended Teaching Mode of Economic and Management Courses in Local Colleges and Universities [J]. Science and Technology Entrepreneurship Monthly, 2018, 31 (03): 114-116.

[3] Wu Shilin, Guan Fuquan, Cen Lijuan. Ideas on Mixed Teaching Reform of Public Courses in Economics and Management [J]. Journal of Higher Education, 2018 (05): 133-134+137.

[4] Huang Xi, Zhao Wei. Application of Blended Learning in Experimental Teaching of Economics and Management [J]. Industry \& Technology Forum, 2017, 16 (24): 140-141. 